\title{
Por uma didática decolonial: aproximações teóricas e elementos categoriais
}

\author{
For a Decolonial Didactics: Theoretical Approaches and
}

Categorial Elements

\section{Por una Didáctica Decolonial: Aproximaciones Teóricas y \\ Elementos Categoriales}

\author{
ALDER DIAS \\ WALDIR FERREIRA DE ABREU ${ }^{b}$
}

\section{Resumo}

O presente artigo tematiza a didática, enquanto campo do conhecimento da Pedagogia e como espaço importante de estudo e discussão do pensamento decolonial com vistas a construção de uma didática decolonial. Tem-se como objetivo explicitar elementos teóricos que contribuem com a constituição de uma didática decolonial. Consiste em uma pesquisa bibliográfica. Entre os referenciais teóricos constam autores do pensamento decolonial e da didática crítica intercultural. Abordam-se elementos históricos e conceituais que demarcam o pensamento decolonial, a pedagogia decolonial e a didática crítica intercultural, que possibilitam o desvelar epistemológico de realidades invisibilizadas, de enfrentamento crítico ao paradigma moderno/colonial e as relações de colonialidade formadas nos movimentos hegemônicos mundiais, forjados desde o processo de conquista das Américas. Retoma-se o pensamento de Candau desde a proposta de uma didática fundamental na década de 1980 aos dias atuais, momento em que defende uma didática crítica intercultural. No diálogo com esse percurso, propõe-se a didática decolonial. Conclui-se, entre outros elementos, que uma prática didática decolonial precisa assumir a alteridade como pressuposto ético-políticoeducativo, sobretudo considerando os sujeitos historicamente marginalizados, oprimidos e subalternizados da sociedade e do sistema educacional, comumente imersos em lógicas opressoras, monoculturalistas e instrumentais.

\footnotetext{
a Universidade Federal do Amapá (UNIFAP), Macapá, AP, Brasil. Mestre em Educação, e-mail: alderdiass@yahoo.com.br

b Universidade Federal do Pará (UFPA), Belém, PA, Brasil. Doutor em Ciências Humanas, e-mail: awaldir@ufpa.br
} 
Palavras-chave: Didática Crítica Intercultural. Pensamento decolonial. Pedagogia decolonial. Didática decolonial.

\begin{abstract}
The present article thematizes didactics, as a field of knowledge of Pedagogy and as an important space of study and discussion of the decolonial thinking, to construct a decolonial didactics. The objective is to explain theoretical elements that contribute to the constitution of a decolonial didactics. It consists of a bibliographical research. Among the theoretical references are authors of decolonial thinking and intercultural critical didactics. Historical and conceptual elements that define decolonial thinking, the decolonial pedagogy, and the intercultural critical didactics are discussed; those enable the epistemological unveiling of invisible realities, of critical confrontation against the modern/colonial paradigm and the relations of coloniality formed in the world hegemonic movements, forged since the process of conquest of the Americas. The discourse of Candau is taken up from the proposal of a fundamental didactics in the 1980s to the present day when she advocates intercultural critical didactics. In dialogue with this course, the decolonial didactics is proposed. It is concluded, among other elements, that a decolonial didactic practice needs to take on alterity as an ethical-political-educational presupposition, especially considering the subjects who are historically marginalized, oppressed, a subaltern in society and the educational system, usually immersed in oppressive, monocultural and instrumental logics.
\end{abstract}

Keywords: Intercultural Critical Didactics. Decolonial thought. Decolonial pedagogy. Decolonial didactics.

\title{
Resumen
}

El presente artículo tiene como tema la didáctica, en cuanto campo del conocimiento de la Pedagogía y como espacio importante de estudio y discusión del pensamiento decolonial para la construcción de una didáctica decolonial. Se tiene como objetivo explicitar elementos teóricos a contribuir con la constitución de una didáctica decolonial. Consiste en una investigación bibliográfica. Entre los referentes teóricos constan autores del pensamiento decolonial y de la didáctica crítica intercultural, que posibilitan el desvelar epistemológico de realidades de perspectivas invisibles, de enfrentamiento crítico al paradigma moderno/colonial y las relaciones de colonialidad creadas en los movimientos hegemónicos mundiales, desde el proceso de conquista de las Américas. Se retoma el pensamiento de Candau desde la propuesta de una didáctica fundamental en la década de 1980 a los días actuales, momento en que defiende una didáctica crítica intercultural. En el diálogo con ese recorrido, se propone la didáctica decolonial. Se concluye, entre otros elementos, que una práctica didáctica decolonial necesita asumir la alteridad como pressuposición ética, política y educativa, principalmente a considerarse sujetos históricamente marginados, oprimidos, subalternizados de la sociedad y del sistema educativo, inmersos en lógicas opresoras, monoculturalistas e instrumentales.

Palabras clave: Didáctica decolonial. Acercamientos teóricos. Elementos Categoriales. 


\section{Introdução}

O propósito do artigo é explicitar elementos teóricos para contribuir com a constituição de uma didática decolonial que se desdobre do Pensamento Decolonial (compreendido como atitude de resistência e como razão ${ }^{1}$ ) e mais precisamente de pedagogias decoloniais.

Contudo, de um lado, é preciso deixar claro, para justificar o propósito do artigo, que o Pensamento Decolonial, no sentido estrito de uma razão, é uma construção recente, que tem como um dos marcos a constituição da rede modernidade/colonialidade nos anos 1990, que “[...] reúne nomes como Enrique Dussel, Walter Mignolo, Aníbal Quijano, Catherine Walsh, Ramón Grosfoguel, Santiago Castro-Gómez, Edgardo Lander, Arturo Escobar, Nelson MaldonadoTorres, entre outros” (MOTA NETO, 2016, p. 17, grifo nosso).

Por outro lado, são recentes os processos de construção de pedagogias decoloniais como resultados praxiológicos do Pensamento Decolonial. Nesse âmbito, têm-se as contribuições de Walsh (2009), Palermo (2014) e Mota Neto (2016). Mais recentes ainda, são os desdobramentos para os campos da Pedagogia como ciência, no sentido por exemplo, de uma didática decolonial. A esse respeito, encontrou-se apenas a produção de Ramalho (2017) que aborda um diálogo entre as pedagogias decoloniais e a didática do ensino de História, no contexto argentino.

Nesse estudo, o autor traz como contribuição três indicativos para a constituição de uma didática decolonial com foco para o ensino de história: deixar para traz o ensino da história "única" e de narrativa universal, que ignora e invisibiliza sujeitos e experiências, sobretudo fora do eixo europeu, lembrando que o nosso está repleto de histórias de libertação; potencial para compreender nossa história a partir dos diálogos sul-sul; e valorizar outras experiências de "modernidade" e ouvir histórias silenciadas para quebrar discursos e práticas racistas (RAMALHO, 2017).

No contexto brasileiro, embora a produção de uma abordagem crítica de didática como "didática fundamental" surja desde a década de 1980, é apenas na

\footnotetext{
${ }^{1}$ Cf. Seção 3: "Pensamento decolonial: caracterização histórica e definição de categorias centrais". 
primeira década dos anos 2000 que se passa a relacionar a didática com o embasamento teórico de Catherine Walsh, intelectual pertencente à rede modernidade/colonialidade (OLIVEIRA; CANDAU, 2010), o que enseja mais recentemente o desenvolvimento de uma Didática Crítica Intercultural (CANDAU, 2018).

Nesse sentido, considerando-se que o Pensamento Decolonial e a Pedagogia Decolonial estão em pleno processo de construção; que são recentes as produções científicas sobre uma didática decolonial; que no âmbito de Brasil há produções científicas de didática que se relacionam com autores que advogam o pensamento decolonial, levanta-se a seguinte questão: que elementos teóricos podem contribuir para a constituição de uma didática decolonial?

Metodologicamente, o artigo resulta de uma pesquisa de abordagem qualitativa, bibliográfica, ancorada em elementos da Análise de Conteúdo (BARDIN, 1991) com base em produções sobre a Didática Fundamental, a Didática Crítica Intercultural, o Pensamento Decolonial e as pedagogias decoloniais.

Por fim, longe de se esgotar a temática, a presente pesquisa demonstra com análise conceitual que é preciso avançar na construção de uma didática decolonial sensível aos sujeitos e grupos subalternizados pelo padrão de poder da colonialidade, mantendo o diálogo com antecedentes teórico-práticos, como a própria educação popular, a educação do campo, a educação dos movimentos sociais, a educação das minorias étnicas, entre outras.

\section{Metodologia}

Ao se considerar que o tema do artigo é a didática em perspectiva decolonial, optou-se por ancorar epistemologicamente a presente pesquisa no âmbito do Pensamento Decolonial/decolonialidade, que, como será destacado na seção posterior, assume duplo papel: o de suporte compreensivo do encobrimento pelo dominador da alteridade dos sujeitos "não-europeus" desde o ano de 1492 — e de toda a diversidade étnica que conforma o mundo para além do eurocentrismo - mas também como o de promotora/libertadora de modos "outros" de existir, colocandose contra o projeto da colonialidade/modernidade e seu mito sacrificial. 
Metodologicamente, o presente estudo se situa no âmbito da abordagem qualitativa, com base na pesquisa bibliográfica. Sobre a Didática, foram analisadas produções científicas de Candau, que formulou os fundamentos da Didática Fundamental e atualmente defende a Didática Crítica Intercultural. Escolha que se deu porque esta última proposição de didática se aproxima da decolonialidade.

As análises das produções bibliográficas foram sistematizadas com base em categorias analíticas e em categorias temáticas, elementos próprios da Análise de Conteúdo (BARDIN, 1991). Nesse sentido, para efeito deste estudo, ao se compreender a Didática como campo do conhecimento em Pedagogia e como disciplina presente nos cursos de formação de professores (HEGETO, 2014), tendo clareza de que: “O objeto da didática é o processo ensino-aprendizagem” (CANDAU, 1996, p. 13), que por vez, "é um processo em que está sempre presente, de forma direta ou indireta, o relacionamento humano" (p. 13), adotaram-se as seguintes categorias analíticas: Didática Fundamental (CANDAU, 1996) e Didática Crítica Intercultural (CANDAU, 2018).

Em relação à decolonialidade, apresentam-se as principais categorias analíticas: colonialismo (QUIJANO, 2010); colonialidade (DUSSEL, 1993; MIGNOLO, 2008); projeto de modernidade eurocêntrica (DUSSEL, 1993); atitude decolonial e razão descolonial (MALDONADO-TORRES, 2008), decolonialidade (MALDONADOTORRES, 2008; MIGNOLO, 2008); transmodernidade (DUSSEL, 1993) e pedagogias decoloniais (WALSH, 2009; MOTA NETO, 2016).

Por fim, os dados das leituras foram organizados em fichamentos e em quadros esquemáticos e analisados com base em três categorias temáticas que dão nome às seções 3, 4 e 4.1, do presente do artigo.

\section{Pensamento decolonial: caracterização histórica e definição de categorias centrais}

Essa seção defende a seguinte ideia central: "Os povos originários das Américas tinham seus processos de socialização, educação, formação de saberes, 
modos de pensar e de pensar-se. Tinham suas leituras de seus mundos e de si" (ARROYO, 2014, p. 155). Contudo, esses processos e leituras não foram considerados pelos povos dominadores, desde o ano de 1492, com a conquista das Américas, ao mesmo tempo em que se "encobriu" a alteridade do "outro" nãoeuropeu, o índio (DUSSEL, 1993), e, mais atualmente, toda diversidade étnica e cultural que não proceda do "centro" euro-norte-americano (DUSSEL, 2012).

Para sustentar essa ideia central, realiza-se uma caracterização histórica do pensamento decolonial, assim como são destacadas categorias relevantes para sua compreensão: o colonialismo, a colonialidade e o projeto de modernidade eurocêntrica — com seu conteúdo semântico positivo como razão emancipadora e seu conteúdo semântico negativo: o mito sacrificial, o mito da modernidade.

No século XV, algumas nações da Europa, como Espanha, Portugal, França, Inglaterra e Holanda passam a expandir seus territórios e a engendrar uma forma de dominação e de exploração não apenas de territórios, mas de outros povos. Este fato histórico-político ficou conhecido como Colonialismo, que de acordo com Quijano (2010, p. 84), trata-se de “[...] uma estrutura de dominação/exploração onde o controle da autoridade política, dos recursos de produção e do trabalho de uma população determinada domina outra de diferente identidade e cujas sedes centrais estão, além disso, localizadas noutra jurisdição territorial”.

O Colonialismo, como estrutura de poder já extinta na história, ensejou o surgimento da colonialidade como conjunto de forças interiores, que mantêm hierarquias distintas sobre expressões existenciais entre povos dominados e dominadores, que se sustentam em uma classificação étnica/racial. Nesse sentido, a colonialidade surge na América e a partir dela se expande, mundializa-se e se constitui em um dos elementos de dominação do capitalismo (QUIJANO, 2010).

Do Colonialismo e da colonialidade se desdobra outro fator determinante para o domínio europeu: a modernidade. Dussel (1993; 2000) afirma haver duas concepções de modernidade. A primeira é a concepção de modernidade "eurocêntrica", a indicar que fenômenos intraeuropeus, datados a partir do século XVI, constituem os acontecimentos históricos-chave para a implantação da subjetividade moderna, como é o caso da expansão marítima de Portugal e Espanha (DUSSEL, 2000). 
A outra concepção de modernidade - base crítica desse trabalho - é demarcada por um fato histórico que de antemão a faz sair da circularidade dos acontecimentos intraeuropeus. Trata-se da "descoberta" das Américas, em 1492, pois a partir desse marco mundial a Europa se coloca como "centro" e constitui as outras culturas como suas periferias. Esse fato proporciona a organização de um mundo colonial e o usufruto de suas "vítimas" (povos originários conquistados, violentados e colonizados) em nível pragmático e econômico. Por isso, para Dussel (1993), o ano de 1492 é a data de nascimento da modernidade.

$\mathrm{Na}$ perspectiva de Dussel (1993), essas concepções de modernidade apresentam dois conteúdos semânticos. O primeiro é seu conteúdo fundamental e positivo, isto é: a modernidade como emancipação racional, que é um esforço da razão como processo crítico, que abre à humanidade as portas de um novo desenvolvimento histórico do ser humano. O segundo é seu conteúdo semântico secundário e negativo, que se refere à modernidade como justificativa de uma práxis irracional de violência: o irracionalismo moderno.

Esse segundo conteúdo semântico sustenta o "mito da modernidade", compreendido como um processo de sete momentos, a partir de uma releitura de Dussel (1993): (1) sustenta-se uma posição ideologicamente eurocêntrica de que a civilização moderna é mais desenvolvida, superior; (2) sua superioridade a "obriga" — como exigência moral — a desenvolver aos mais primitivos, rudes, bárbaros, isto é, os povos conquistados; (3) a Europa se coloca como paradigma de desenvolvimento (falácia desenvolvimentista); (4) a violência como "guerra justa" se impõe aos povos conquistados que resistem ao processo civilizador; (5) a civilização moderna eurocêntrica interpreta a violência como ato inevitável no sentido próximo de um "sacrifício salvador"; (6) os povos conquistados são culpados pela violência, a guerra justa - a subjetividade moderna eurocêntrica se coloca inocente e como emancipadora da culpa de suas próprias vítimas; (7) por fim, apresenta-se a violência como "os custos" da modernização dos povos "atrasados" (imaturos), das raças escravizadas, do sexo feminino apresentado como frágil etc. 
Dando sequência à trama conceitual, cabe explicitar um terceiro desdobramento: a decolonialidade. Nas palavras de Mignolo (2008, p. 249, tradução nossa):

O argumento básico (quase um silogismo) é o seguinte: se a colonialidade é constitutiva da modernidade e a retórica salvacionista da modernidade pressupõe a lógica opressiva e condenatória da colonialidade [...], essa lógica opressiva produz uma energia de descontento, de desconfiança, de desprendimento entre aqueles que reagem ante a violência imperial. Essa energia se traduz em projetos de decolonialidade que, em última instância, também são constitutivos da modernidade.

Portanto, a decolonialidade surge como energia de resistência no sentido dialético-material ante à colonialidade e à modernidade com mito sacrifical. Essa definição de decolonialidade fundamenta-se na materialidade das vítimas negadas que, tomadas por uma postura crítica, buscam afirmar suas vidas ante o projeto de morte da modernidade/colonialidade, desde o ano de 1492.

Nessa lógica, Maldonado-Torres apresenta a atitude "des-colonial" como conceito apropriado a desvelar o sentido material da decolonialidade como energia de resistência. Para o autor:

A atitude des-colonial nasce quando o grito de espanto ante o horror da colonialidade se traduz em uma postura crítica ante o mundo da morte colonial e em uma busca pela afirmação da vida daqueles que são mais afetados por tal mundo (2008, p. 66-67, tradução nossa).

Contudo, o pensamento decolonial passa a ganhar mais contundência teórica e epistemológica apenas por volta dos anos 1990, com a constituição da rede modernidade/colonialidade, que é caracterizada por Oliveira e Candau (2010, p. 17) da seguinte maneira: “O grupo é formado predominantemente por intelectuais da América Latina e apresenta caráter heterogêneo e transdisciplinar". Este grupo mantém diálogos e atividades acadêmicas, tendo como foco a construção de uma sociedade não eurocentrada, em relação ao projeto de civilização.

A esse ponto do artigo, cabe destacar que a decolonialidade se configura não apenas como energia de resistência (atitude decolonial), mas também como razão “des-colonial”, isto é, uma postura ético-política e teórica que, ao se opor à mentira e à hipocrisia moderna colonial, enfoca novas bases para o conhecimento e, sobretudo, busca caminhos para um humanismo de reconhecimento das alteridades em nível planetário (MALDONADO-TORRES, 2008). 
O pensamento decolonial — como energia de resistência e como razão "descolonial" - está para além de ser representado apenas por intelectuais. De fato, o pensamento decolonial opera por mão dupla: as expressões de luta e resistência contra a modernidade/colonialidade e as elaborações teóricas de intelectuais, sobretudo, os engajados com a porção sul do planeta.

Nesse sentido, têm-se as pedagogias decoloniais como expressões de luta e resistência, mas também como elaborações teóricas que se desdobram da decolonialidade, conforme aponta Walsh (2009 p. 27):

[...] pedagogias que dialogam com os antecedentes crítico-políticos, ao mesmo tempo em que partem das lutas e práxis de orientação decolonial. Pedagogias que [...] enfrentam o mito racista que inaugura a modernidade [...] e o monólogo da razão ocidental; pedagogias que se esforcem por transgredir, deslocar e incidir na negação ontológica, epistêmica e cosmogônico-espiritual que foi, e é, estratégia, fim e resultado do poder da colonialidade.

Portanto, a pedagogia decolonial é uma denominação genérica dada às pedagogias críticas que, ao se alinharem praxiologicamente ao pensamento decolonial, transgridem às inúmeras expressões da colonialidade e da modernidade como mito sacrificial.

Nessa direção, Mota Neto (2016) também expressa uma definição de pedagogia decolonial que tem sua identidade ancorada na práxis da luta contra a colonialidade/"modernidade", que se dá por meio de processos de formação humana, tendo em vista a construção de uma sociedade justa, solidária, livre e amorosa:

[...] a pedagogia decolonial refere-se às teorias-práticas de formação humana que capacitam os grupos subalternos para a luta contra a lógica opressiva da modernidade/colonialidade, tendo como horizonte a formação de um ser humano e de uma sociedade livres, amorosos, justos e solidários (MOTA NETO, 2016, p. 318).

Nota-se que em ambas as definições há em comum o sentido da resistência como práxis humana contra a colonialidade/"modernidade". Nesse sentido, cabe destacar a relação entre estas definições de pedagogia decolonial e seus desdobramentos para uma didática decolonial no contexto brasileiro. 


\section{Por uma didática decolonial: contribuições da didática crítica intercultural para a constituição de um mundo}

“outro"

Candau (1996) destaca que dos anos 1960 a 1970 a didática foi abordada com ênfase no tecnicismo, com base no pressuposto da neutralidade. Dos anos 1970 a 1980, a ênfase se deu na dimensão política, que é inerente a toda e qualquer prática pedagógica, mas com negação da dimensão técnica. É nessa conjuntura que a autora afirma a confluência dialética do técnico e do político a ser trabalhada conscientemente rumo a uma didática fundamental.

Para tanto, essa perspectiva de didática apresenta a seguinte configuração:

A perspectiva fundamental da Didática assume a multidimensionalidade do processo ensino-aprendizagem e coloca a articulação das três dimensões, técnica, humana e política, no centro configurador de sua temática.

Procura partir da análise da prática pedagógica concreta e de seus determinantes.

Contextualiza a prática pedagógica e procura repensar as dimensões técnica e humana, sempre "situando-as".

Analisa as diferentes metodologias explicitando seus pressupostos, o contexto em que foram geradas, a visão de homem, de sociedade, de conhecimento e de educação que veiculam.

Elabora a reflexão didática a partir da análise e reflexão sobre experiências concretas, procurando trabalhar continuamente a relação teoria-prática.

[...] parte do compromisso com a transformação social, com a busca de práticas de pedagógicas que tornem o ensino de fato eficiente [...] para a maioria da população. Ensaia, analisa, experimenta. [...] Promove o trabalho em comum de professores e especialistas. Busca as formas de aumentar a permanência das crianças na escola. Discute a questão do currículo em sua interação com uma população concreta e suas exigências, etc. (CANDAU, 1996, p. 21).

Contudo, a partir dos anos 1990, tendo-se a conjuntura negativa das políticas neoliberais, inclusive para a educação, acrescenta-se a essa perspectiva de didática fundamental alguns pontos emergentes "como os relativos ao cotidiano escolar, ao saber docente, e às relações entre escola e cultura" (CANDAU, 2018, p. 9), sendo "[...] a primeira vez que esta temática emerge na nossa produção sobre a didática" (p. 9).

Portanto, a didática para Candau consiste em uma didática crítica que se consolida como uma das mais influentes referências, desde os anos 1980, sobretudo porque traz em seu bojo princípios de reconhecimento e valorização do sujeito como 
educando, como a categoria multidimensionalidade, a análise da prática pedagógica em sua concreticidade e, considerando seus determinantes estruturais e superestruturais, a contextualização, a análise filosófico-educacional dos pressupostos da prática educativa, a valorização da relação entre teoria e prática, o compromisso assumido em favor da transformação social, a ênfase no trabalho coletivo entre os profissionais da educação, o interesse para com a permanência com qualidade das crianças no ambiente escolar e, fundamentalmente, aborda o currículo em sua interação com a população, compreendida em suas necessidades materiais.

Portanto, desde os anos 1990 essa perspectiva de didática passa a integrar criticamente a relação entre escola e cultura(s). Período marcado pela criação do Grupo de Estudos sobre Cotidiano, Educação e Cultura(s), conforme assevera a autora:

É importante salientar que em 1996, surge o GECEC - Grupo de Estudos sobre Cotidiano, Educação e Cultura(s), vinculado ao Departamento de Educação da PUC-Rio, que coordenamos e através dele vimos desenvolvendo sistematicamente pesquisas que aprofundam desde diferentes pontos de vista estas relações (CANDAU, 2018, p. 11).

Nos anos 2000, Candau (2001), ao participar da Mesa: “20 anos de ENDIPE”, apresenta uma agenda de trabalho. Primeiramente, afirma que a construção da didática a partir do início dos anos 1980 esteve alinhada à perspectiva crítica. Situa essa produção científica sobre didática como parte da modernidade no sentido mesmo de horizontes utópicos e metanarrativas.

Certamente este universo pode ser identificado como característico da modernidade, enquanto enfatiza a capacidade dos indivíduos situarem-se criticamente diante da realidade, exercerem sua responsabilidade social e construírem o mundo e a história a partir de um horizonte utópico baseado na liberdade, na igualdade e na racionalidade (CANDAU, 2001, p. 152).

Nesses termos, baseada em uma filosofia oriunda do centro da geopolítica do conhecimento (MIGNOLO, 2014), a autora passa a adotar a abordagem da crítica pós-moderna sobre pretexto de englobar uma pluralidade de abordagens e enfoques para que se repense a pedagogia e a didática, sem perder de vista a criticidade e o foco na categoria cultura(s):

Portanto, se trata de trabalhar as possíveis articulações e de, sem negar o horizonte emancipador da perspectiva crítica, incorporar novas questões que emergem da perspectiva pós-moderna, como as relativas à subjetividade, à diferença, à construção de 
identidades, à diversidade cultural, à relação saber-poder, às questões étnicas, de gênero e sexualidade etc. A categoria cultura é, sem dúvida, central nesta perspectiva (CANDAU, 2001, p. 153).

Com base na crítica pós-moderna, própria da hegemonia epistêmica do centro do sistema-mundo (DUSSEL, 2000) a autora atualiza seu referencial de didática crítica, incorporando cada vez mais as categorias cultura e cotidiano escolar como meios para a reinvenção da educação escolar e da didática.

No sentido positivo de constante reinvenção teórico-prática, ainda nos anos 2000, a autora passa a ter contato com o referencial da rede modernidade/colonialidade, por meio de atividades acadêmicas com Catherine Walsh, integrante da rede:

Em outubro de 2007, realizamos um seminário presencial, no Rio de Janeiro, com a professora Catherine Walsh, em que discutimos e aprofundamos a perspectiva desenvolvida pelo grupo "Modernidade/Colonialidade", especialmente em suas relações com a educação (OLIVEIRA; CANDAU, 2010, p. 21).

Ao incorporar a interculturalidade crítica abordada por Walsh (2009), Candau e parceiras de pesquisa passam a desenvolver/construir uma didática na perspectiva multi/intercultural (CANDAU; KOFF, 2006; CANDAU; LEITE, 2007), perspectiva essa assumida mais recentemente como "Didática Crítica Intercultural” (CANDAU, 2018), que se alicerça em três teses fundamentais:

1. A educação escolar, configurada a partir da modernidade, está instada a ser "reinventada" para enfrentar as questões atuais de um mundo complexo, desigual, diverso e plural.

2. A perspectiva crítica da Didática, que teve um amplo e significativo desenvolvimento no nosso país, especialmente a partir dos anos 80 , está hoje desafiada por questões que exigem novos desenvolvimentos, buscas, preocupações e pesquisas.

3. É a partir do enfoque intercultural que apostamos na construção deste processo de ressignificação da Didática (CANDAU, 2018, p. 111).

Note-se que essa perspectiva de didática mantém sua base crítica proveniente dos anos de 1980 e se centra na interculturalidade como elemento principal para desenvolver/construir perspectivas de didática que visem responder às demandas de um mundo complexo, desigual, diverso e plural, de acordo com o referencial da pósmodernidade eurocentrada, que se sustenta a autora.

A essa altura, cabe sintetizar que a interculturalidade crítica assumida por Candau a partir do contato com Walsh tem um fundamento: "partir do problema estrutural-colonial-racial e dirigir-se para a transformação das estruturas, instituições 
e relações sociais e a construção de condições radicalmente distintas" (WALSH, 2009, p. 23).

Nesse sentido, a interculturalidade crítica envolve não apenas lutas por transformações estruturais que envolvem questões de ordem política, social e cultural, mas "se preocupa também com a exclusão, negação e subalternização ontológica e epistêmico-cognitiva dos grupos e sujeitos racializados" (WALSH, 2009, p. 23), além de também se opor criticamente às práticas que naturalizam relações assimétricas de dominação, na medida em que não destacam as desigualdades e as diferenças. Por este motivo, Candau aposta na interculturalidade crítica como um dos meios para ressignificação da didática.

Conforme afirma Candau (2018, p. 131), a Didática Crítica Intercultural assume claramente que: "O importante é reconhecer a existência de diversos saberes e conhecimentos no cotidiano escolar e procurar estimular o diálogo entre eles, assumindo os conflitos que emergem desta interação”. Nesse sentido, viabiliza a incorporação de diferentes universos culturais dentro da escola, que é compreendida como espaço dinâmico, vivo.

Essa proposição de didática não perde a multidimensionalidade contextual de onde ocorrem as práticas educativas, assim como tem claro que entre suas finalidades sociais mantém a criticidade e o comprometimento para com as mudanças sociais, na medida em que pretende "fortalecer perspectivas educativas e sociais orientadas a radicalizar os processos democráticos e articular igualdade e diferença, em todos os níveis e âmbitos, do macrossocial à sala de aula” (CANDAU, 2012, p. 133).

\section{Por uma didática decolonial: alguns elementos teóricos}

Uma didática decolonial precisa assumir para si a identidade decolonial no sentido das atitudes de resistência e da razão decolonial que se coadunam contra o senhorio da colonialidade/modernidade eurocêntrica e seu mito sacrificial, sem deixar de lado a luta para estabelecer uma sociedade justa, por meio de insurgências e resistência em nível político, social, cultural, ontológico, epistemológico e cosmogônico-espiritual, como apontam Walsh (2009) e Mota Neto (2016). 
Nesses termos, é fundamental assumir a identidade decolonial porque, por exemplo, a despeito do caráter crítico e emancipador da didática proposta por Candau, essa se situa na esteira da interculturalidade crítica que, apesar de se relacionar com a decolonialidade, também apresenta suas próprias distinções em relação a esta, não podendo as duas serem assumidas como sinônimas.

A interconexão entre a interculturalidade crítica e a decolonialidade é assim destacada: "a interculturalidade crítica e a decolonialidade [...] são projetos, processos e lutas que se entrecruzam conceitualmente e pedagogicamente, alentando forças, iniciativas e perspectivas éticas que fazem questionar, transformar, sacudir, rearticular e construir" (WALSH, 2009, p. 25).

Outro elemento importante para a constituição de uma didática decolonial é quanto ao seu objeto de estudo. O que se quer dizer é que uma didática identificada com a luta/projeto decolonial deve, de antemão, abranger - desde o nível antropológico - seu objeto de estudo para não apenas o processo de ensinoaprendizagem na perspectiva da educação escolar e da formação de profissionais da educação. Ou seja, objeto da didática decolonial precisa ser os processos de ensinoaprendizagem que ocorrem nos diferentes espaços educativos (inclusive nas escolas com suas salas de aula), nas quais interagem sujeitos-educandos e sujeitos-educadores (desde educadores populares até profissionais da educação escolar).

Sem essa redefinição radical do objeto de estudo da didática, seus processos formativos e suas pesquisas tenderão ao formalismo e ao distanciamento das reais necessidades dos principais sujeitos a quem se destinam os processos educacionais: o povo, em sua riqueza existencial, histórica, cultural, social e epistêmica.

A didática, sem essa radicalidade quanto ao seu objeto de estudo, deixa de lado a materialidade da decolonialidade como "energia de resistência" dos que sofrem/sofreram de opressão, marginalização e discriminação de diversas de formas, de modo que esses sujeitos tendem a não mais se reconhecer identitariamente na educação escolar, pois, entre outros aspectos, têm desvalorizados seus modos concretos de existir, suas culturas e educações populares, o que, por fim, tende a reproduzir a lógica dominadora da colonialidade/modernidade e seu mito sacrificial.

Nesse sentido, Joaquim Maria destaca (1996, p. 110-111): 
É importante perceber que a pedagogia vigente tem desvalorizado a cultura popular seguindo a lógica dos colonizadores que produziram em terras ameríndias a desvalorização da cultura indígena, negra... e orientando a sua prática a partir da cultura de "centro". É normal no Brasil um professor pedir aos seus alunos que mencionem alguns exemplos de obras de arte e a resposta será: Monalisa, de Da Vinci, pinturas de Picasso, Sinfonias de Beethoven, etc., e dificilmente fala-se em algo brasileiro.

A base teórico-prática se constitui como o terceiro elemento central para a constituição de uma didática decolonial. Na perspectiva do pensamento decolonial, sobretudo com base em Dussel (1993; 2000; 2012), deixa-se de lado as bases filosóficas eurocêntricas da pós-modernidade porque - como visto anteriormente - a modernidade eurocêntrica é constitutiva do padrão de poder da colonialidade/modernidade e seu mito sacrificial. Então, factualmente, não se considera uma pós-modernidade se continua atual tal padrão de poder, que inclusive contribui para a manutenção do capitalismo.

O ponto de partida teórico e geopolítico da decolonialidade, então, não é a pós-modernidade, mas a transmodernidade de Dussel (1993), que se ancora fundamentalmente no reconhecimento material e ético-político da alteridade dos sujeitos negados em seus modos concretos de se fazer "no" e "com" o mundo ante o projeto da colonialidade/modernidade e seu mito sacrificial. Pela transmodernidade, não se nega o projeto de modernidade eurocentrada, considera-se sua positividade semântica como razão emancipadora, mas transformando-a em razão libertadora.

Nesse sentido: "É a partir desta abrangência teórica e da exigência de factibilidade de um mundo que inclua o oprimido, a vítima é que a transmodernidade se apresenta como novo projeto de libertação política, econômica, ecológica, pedagógica, religiosa, etc.” (DIAS; OLIVEIRA, 2012, p. 26).

Pela transmodernidade, desde a ética da libertação, o "outro" se revela face a face como "ser" (em termos ontológicos). Considera-se positivamente os modos de existir da diversidade de sujeitos e coletivos estereotipados como incultos, inumanos, bárbaros ou inferiores, por questões de classe social, raça, gênero etc., no bojo de uma sociedade machista, patriarcal e capitalista, mas que se pretende transformadora de todos esses condicionantes desumanizantes da colonialidade/modernidade. 


\section{Considerações finais}

O artigo objetivou destacar elementos teóricos que contribuem com a constituição de uma didática decolonial. Para tanto, primeiramente se realizou uma caracterização histórica e conceitual do pensamento decolonial e da pedagogia decolonial, para em seguida analisar como tem ocorrido a construção da didática em perspectiva crítica no Brasil.

Tendo-se como referência o legado de Candau, identificou-se que sua proposição teórica se sustenta na produção crítica da Didática, desde os anos de 1980, em marcos da pós-modernidade crítica e, fundamentalmente, na interculturalidade crítica. Considera-se que sua proposição de didática contribui significativamente para o avanço do reconhecimento das alteridades historicamente negadas e silenciadas, mas não se reconhece como decolonial, antes assume a identidade da Didática Crítica Intercultural.

Entre os principais elementos considerados para a constituição de uma didática decolonial, destacam-se: tomar para si a identidade decolonial, o que implica em reconhecer o padrão de poder da modernidade/colonialidade e seu mito sacrificial; a partir de uma pedagogia decolonial, redefinir o objeto de estudo da didática para todo processo ensino-aprendizagem a ocorrer em diferentes espaços educativos, inclusive os escolares; também se considera assumir a transmodernidade (e não a pósmodernidade, por mais crítica que pareça) como um ponto de partida teórico da didática, justamente por se relacionar ao projeto de libertação das amarras da colonialidade/modernidade.

Conclui-se que o presente artigo apenas apresenta algumas contribuições em nível teórico para se constituir uma didática decolonial. Cabe avançar no desenvolvimento desta didática das seguintes formas: ouvindo sujeitos e grupos subalternizados pelo padrão de poder da colonialidade; percebendo as atitudes de resistência de sujeitos e grupos sociais diversos; dialogando com movimentos críticos de matriz decolonial como a própria educação popular e a educação do campo; e analisando criticamente contributos de autores como Enrique Dussel, que possui uma 
gama de categorias conceituais que precisam ser melhor explicitadas e confrontadas com experiências decoloniais.

\section{Referências}

ARROYO, M. G. Outros sujeitos, outras pedagogias. 2a ed. Petrópolis: Vozes, 2014.

BARDIN, L. Análise de Conteúdo. Lisboa. Edições 70, 1991.

CANDAU, V. M. F. A Didática e a formação de educadores - da exaltação à negação: a busca da relevância. In: CANDAU, V. M. F. (Org.). A Didática em Questão. 13ª ed. PetrópolisRJ: Vozes, 1996.

CANDAU, V. M. F. Mesa 20 anos de ENDIPE. A Didática hoje: uma agenda de trabalho. In: CANDAU, V. M. F. (Org.). Didática, Currículo e Saberes Escolares. $2^{\mathrm{a}} \mathrm{ed}$. Rio de Janeiro: DP\&A, 2001.

CANDAU, V. M. F.; KOFF, A. M. N. S. Conversas com... sobre a didática e a perspectiva multi/intercultural. Educ. Soc., Campinas, v. 27, n. 95, p. 471-493, mai./ago. 2006.

CANDAU, V. M. F.; LEITE, M. S. A didática na perspectiva multi/intercultural em ação: construindo uma proposta. Cadernos de Pesquisa, São Paulo, v. 37, n. 132, p. 731-758, set./dez. 2007.

CANDAU, V. M. F. Escola, Didática e Interculturalidade: desafios atuais. In: CANDAU, V. M. F. (Org.). Didática Crítica Intercultural. 2ª reimp. Petrópolis: Vozes, 2018.

DIAS; A. S.; OLIVEIRA, I. A. Um olhar dusseliano sobre a Pedagogia do Oprimido de Paulo Freire: contribuições para as Epistemologias do Sul. In: OLIVEIRA, I. A.; ARAÚJO, M. D.; CAETANO, V. N. S. (Orgs.). Epistemologia e Educação: reflexões sobre temas educacionais. Belém: PPGED-UEPA, 2012. Disponível em: $<$ http://ccse.uepa.br/ppged/wp-content/uploads/producoes/LIVRO_

EPISTEMOLOGIA_E_EDUCAO_PDF_2.pdf>. Acesso em: 13 nov. 2018.

DUSSEL, E. 1492: o encobrimento do outro: a origem do mito da modernidade. Petrópolis: Vozes, 1993.

DUSSEL, E. Europa, Modernidad e Eurocentrismo. In: LANDER, E. (Org.). La colonialidad del saber: eurocentrismo y ciencias sociales. Perspectivas Latino-americanas. Buenos Aires: CLACSO, 2000. Disponível em: <http://biblioteca.clacso.edu.ar/clacso/sursur/20100708040738/4_dussel.pdf>. Acesso em: 13 nov. 2017.

DUSSEL, E. Ética da Libertação na Idade da Globalização e da Exclusão. $4^{a}$ ed. Petrópolis: Vozes, 2012.

HEGETO, L. C. F. A didática como disciplina escolar: estudo a partir dos manuais de didática geral. 2014. 212f. Tese (Doutorado em Educação) — Universidade Federal do Paraná, Curitiba-PR, 2014. 
MARIA, J. P. Novos Paradigmas Pedagógicos para uma filosofia da educação. $2^{\mathrm{a}}$ ed. São Paulo: Paulus, 1996.

MALDONADO-TORRES, N. La descolonización y el giro des-colonial. Tabula Rasa, Bogotá, Colombia, n. 9, p. 61-72, jul./dic. 2008. Disponível em: <http://www.scielo.org.co/pdf/tara/n9/n9a05.pdf>. Acesso em: 13 nov. 2017.

MIGNOLO, W. La opción de-colonial: desprendimiento y apertura. Un manifiesto y un caso. In: Tabula Rasa. Bogotá, Colombia, n. 8, p. 243-281, jan./jun. 2008. Disponível em: <http://www.scielo.org.co/pdf/tara/n9/n9a05.pdf>. Acesso em: 13 nov. 2017.

MIGNOLO, W. Colonialidad global, capitalismo y hegemonia epistémica. In: MIGNOLO, W. (Comp.). Capitalismo y geopolitica del conocimiento: el eurocentrismo y la filosofia de la liberación en el debate intelectual contemporâneo. 2a ed. Buenos Aires, Del Signo, 2014.

MOTA NETO, J. C. Por uma Pedagogia Decolonial na América Latina: reflexões em torno do pensamento de Paulo Freire e Orlando Fals Borda. Curitiba: CRV, 2016.

OLIVEIRA, L. F; CANDAU, V. M. F. Pedagogia Decolonial e Educação Antirracista e Intercultural no Brasil. Educação em Revista, Belo Horizonte, v. 26, n. 1, p. 15-40, abr. 2010. Disponível em: <http://www.scielo.br/pdf/edur/v26n1/02.pdf>. Acesso em: 13 abr. 2018.

PALERMO, Z. Para una Pedagogía Decolonial. Buenos Aires: Del Signo, 2014.

QUIJANO, A. Colonialidade do poder e classificação social. In: SANTOS, B. de S.; MENESES, M. P. (Orgs.). Epistemologias do Sul. São Paulo: Cortez, 2010.

RAMALHO, F. Pedagogías descoloniales en la Didáctica de la Historia. Estudios de Filosofía Práctica e Historia de las ideas, Argentina, v. 19, p. 1-10, año 2017. Disponível em: <http://qellqasqa.com.ar/ojs/index.php/estudios/article/view/189/233>. Acesso em: 13 nov. 2018.

WALSH, C. Interculturalidade Crítica e Pedagogia Decolonial: in-surgir, re-existir e re-viver. In: CANDAU, V. M. F. (Org.). Educação Intercultural na América Latina: entre concepções, tensões e propostas. Rio de Janeiro: 7 Letras, 2009.

RECEBIDO: 07/12/2018

APROVADO: 02/05/2019
RECEIVED: $12 / 07 / 2018$

APPROVED: 05/02/2019
RECIBIDO: 07/12/2018

APROBADO: 02/05/2019 